\title{
Bradykinin inhibits hepatic gluconeogenesis in obese mice
}

\author{
Carlos Castilho Barros ${ }^{1}$, Anderson Haro ${ }^{1}$, Fernanda Jaqueline Russo ${ }^{1}$, Ines Schadock ${ }^{2}$, Sandro Soares Almeida ${ }^{1}$, \\ Felipe Castellani Reis ${ }^{1}$, Milton Rocha Moraes ${ }^{1}$, Andre Haidar ${ }^{3}$, Aparecida Emiko Hirata ${ }^{3}$, Marcelo Mori ${ }^{1}$, \\ Reury Frank Pereira Bacurau ${ }^{4}$, Martin Würtele ${ }^{5}$, Michael Bader ${ }^{2}$, Joao Bosco Pesquero ${ }^{1}$ and \\ Ronaldo Carvalho Araujo ${ }^{1}$
}

The kallikrein-kinin system (KKS) has been previously linked to glucose homeostasis. In isolated muscle or fat cells, acute bradykinin (BK) stimulation was shown to improve insulin action and increase glucose uptake by promoting glucose transporter 4 translocation to plasma membrane. However, the role for BK in the pathophysiology of obesity and type 2 diabetes remains largely unknown. To address this, we generated genetically obese mice (ob/ob) lacking the BK B2 receptor (obB2KO). Despite similar body weight or fat accumulation, obB2KO mice showed increased fasting glycemia $(162.3 \pm 28.2 \mathrm{mg} / \mathrm{dl}$ vs $85.3 \pm 13.3 \mathrm{mg} / \mathrm{dl})$, hyperinsulinemia $(7.71 \pm 1.75 \mathrm{ng} / \mathrm{ml}$ vs $4.09 \pm 0.51 \mathrm{ng} / \mathrm{ml})$ and impaired glucose tolerance when compared with ob/ob control mice (obWT), indicating insulin resistance and impaired glucose homeostasis. This was corroborated by increased glucose production in response to a pyruvate challenge. Increased gluconeogenesis was accompanied by increased hepatic mRNA expression of forkhead box protein 01 (FoxO1, four-fold), peroxisome proliferator-activated receptor gamma co-activator 1-alpha (seven-fold), phosphoenolpyruvate carboxykinase (PEPCK, three-fold) and glucose-6-phosphatase (eight-fold). FoxO1 nuclear exclusion was also impaired, as the obB2KO mice showed increased levels of this transcription factor in the nucleus fraction of liver homogenates during random feeding. Intraportal injection of BK in lean mice was able to decrease the hepatic mRNA expression of FoxO1 and PEPCK. In conclusion, BK modulates glucose homeostasis by affecting hepatic glucose production in obWT. These results point to a protective role of the KKS in the pathophysiology of type 2 diabetes mellitus.

Laboratory Investigation (2012) 92, 1419-1427; doi:10.1038/labinvest.2012.105; published online 6 August 2012

KEYWORDS: bradykinin; gluconeogenesis; kinin receptor; leptin; ob/ob; obesity

The pathophysiology of type 2 diabetes mellitus (T2DM) involves innumerous metabolic and endocrine alterations, including changes in the carbohydrate, lipid and protein metabolisms. T2DM is directly linked with insulin resistance and the inability of pancreatic beta cells to compensate for these changes. ${ }^{1}$ There is also a strong association between T2DM and obesity ${ }^{1,2}$ that persists independently of gender or ethnic group. In this interaction, the weight gain of obese subjects seems to precede the development of T2DM. ${ }^{3}$

Kinins are vasoactive peptides produced in the circulatory system and other tissues by the action of serine proteases called kallikreins. The kallikrein-kinin system (KKS) modulates pain, vasodilatation, vascular permeability, inflammation and edema and has been linked to insulin resistance. ${ }^{4-7}$
Bradykinin (BK), the agonist of the constitutively expressed $\mathrm{BK}$ B2 receptor (BKB2R), has been reported to increase glucose uptake in skeletal muscle and adipose tissue. ${ }^{8}$ At the same time, the kinin B1 receptor and its agonist, the des-arg ${ }^{9}$ kinin, have been shown to control leptin sensitivity ${ }^{7}$ and insulin secretion. ${ }^{9}$

Despite evidence that acute $\mathrm{BK}$ stimulation improves glucose uptake, the role for BK and BKB2R in the pathophysiology of T2DM is still not clear. In isolated systems, it has been shown that BK can trigger the translocation of the glucose transporter 4 (GLUT4) in adipose tissue and muscle either directly ${ }^{8}$ or by increasing insulin sensitivity. ${ }^{10-12}$ Miyata $e a^{11}$ showed that BK can promote insulin action, augmenting both the phosphorylation of the insulin receptor

\footnotetext{
${ }^{1}$ Department of Biophysics, Federal University of São Paulo, São Paulo, Brazil; ${ }^{2}$ MaxDelbrück Center for Molecular Medicine, Berlin, Germany; ${ }^{3}$ Department of Physiology, Federal University of São Paulo, São Paulo, Brazil; ${ }^{4}$ School of Arts, Sciences and Humanities, Sao Paulo, Brazil and ${ }^{5}$ Department of Science and Technology, Federal University of São Paulo, São Paulo, Brazil

Correspondence: Dr RC Araújo, PhD, Department of Biophysics, Federal University of São Paulo, Rua Botucatu 862, $7^{\circ}$ Andar Vila Clementino, São Paulo, CEP 0423-062, Brazil. E-mail: araujo.ronaldo@unifesp.br 
and the insulin receptor substrate-1 in skeletal muscle and rat L6 myoblasts. Kishi et $a l^{8}$ concluded that BK increases GLUT4 translocation in three different cell lines (L6 myotubes, 3T3-L1 adipocytes and $\mathrm{CHO}$ ) independently on insulin. The effect of BK on glucose uptake is nitric oxide dependent, and thus absent in adipocytes of endothelial NO synthase knockout mice. ${ }^{13}$ Furthermore, BK modulates the feedback inhibition of insulin signaling at the level of insulin receptor substrate- $1 .{ }^{12} \mathrm{BK}$ and nitric oxide are also involved in the effects of leptin on glucose uptake. ${ }^{14}$

Patients treated with angiotensin-converting enzyme inhibitors are less susceptible to develop T2DM. ${ }^{15}$ Angiotensin-converting enzyme has an important role not only by converting angiotensin I to angiotensin II and thereby increasing blood pressure, but also by inactivating kinin peptides. This leads to an increase of kinin levels in patients treated with angiotensin-converting enzyme inhibitors, ${ }^{16-18}$ which has been proposed to protect these patients against T2DM through a mechanism that has not been completely elucidated. ${ }^{19}$

To study the involvement of BK in the pathophysiology of T2DM in the context of obesity, the main etiological cause of T2DM in humans, we studied obese $o b / o b$ mice lacking BKB2R (obB2KO). We were thus able to explore how the deficiency of BKB2R influences glucose homeostasis of obese mice (obWT). As liver is an important organ in the context of $\mathrm{T} 2 \mathrm{DM}$, we were interested in the hepatic metabolism of these animals. ${ }^{20}$ Despite remaining as obese as their $o b / o b$ controls, the obB2KO animals showed increased gluconeogenesis and increased mRNA expression and nuclear accumulation of the transcription factor forkhead box protein O1 (FoxO1). This factor is known to control expression of the enzymes phosphoenolpyruvate carboxykinase (PEPCK) and glucose6-phosphatase (G6Pase) in the liver, both regulatory enzymes of gluconeogenesis. ${ }^{21}$ Consistent with changes in FoxO1, both PEPCK and G6Pase were increased in liver of obB2KO mice. Conversely, intraportal injection of $\mathrm{BK}$ in lean mice acutely decreased FoxO1 and PEPCK mRNA expression in the liver. In this work we show, for the first time, that KKS is strongly involved in glucose metabolism, not only acting in peripheral glucose uptake as previously described but also by affecting hepatic glucose production.

\section{MATERIALS AND METHODS}

\section{Animals}

$\mathrm{Lep}^{\mathrm{ob}} / \mathrm{Lep}^{\mathrm{ob}}(\mathrm{ob} / \mathrm{ob})$ and Bdkrb2${ }^{\mathrm{tm}} / \mathrm{Bdkrb} 2^{\mathrm{tm}}$ mice, referred to below as obWT and $\mathrm{B} 2 \mathrm{KO}$, respectively, all with the C57BL/6J genetic background, were obtained from the Center for the Development of Experimental Animal Models (CEDEME), Federal University of São Paulo (UNIFESP). The infertility of obWT male mice was reverted using the white adipose tissue transplantation technique. ${ }^{22}$ Transplanted $o b / o b$ males were mated with $\mathrm{B} 2 \mathrm{KO}$ females to generate $\mathrm{Lep}^{\mathrm{ob}} \cdot \mathrm{Bdkrb}^{\mathrm{tm}} / \mathrm{Lep}^{\mathrm{ob}} \cdot \mathrm{Bdkrb} 2^{\mathrm{tm}}$, referred below as obB2KO. Mice were fed ad libitum with commercial rodent chow diet
(Nuvi Lab, Nuvital Paraná, Brazil) and neutral pH water, and were maintained under a 12-h light/12-h dark cycle under constant room temperature $\left(22 \pm 1{ }^{\circ} \mathrm{C}\right)$ and humidity $(60 \pm 3 \%)$ conditions. The experiments were carried out with females. All procedures complied with the standards for the care and use of animals as stated in the guide for the care and use of laboratory animals (UNIFESP).

\section{Glycemic Analysis}

All glycemic tests were performed on 3- and 6-month-old mice. The glucose tolerance test and insulin tolerance test were performed in animals fasted for $12 \mathrm{~h}$. To avoid stress there was an interval of 7 days between tests. Glycemia was measured from blood drops from tails using a glucometer (Accu-Chek Advantage). For the glucose tolerance test, $1 \mathrm{~g}$ glucose and for the insulin tolerance test $1 \mathrm{IU}$ of insulin were i.p. injected per kg of body weight.

\section{Serum Insulin Measurements}

To measure serum insulin levels, blood samples were collected at 10 am from 3-and 6-month-old mice, after $12 \mathrm{~h}$ of fasting. The plasma was obtained by centrifugation at $2000 \mathrm{~g}$ and frozen at $-20^{\circ} \mathrm{C}$ until use. The analyses were done with a rat/mouse Insulin ELISA Kit (Millipore).

\section{Morphometric Analysis}

To determine the growth curve and the obesity development, body weight was measured weekly until the mice reached the age of 26 weeks. Thirty-week-old mice were killed and their body weights as well as their organ weight were measured. Liver pieces were saved in buffered formalin or frozen in liquid nitrogen for further analysis. For histopathological analysis, liver sections were stained with hematoxylin and eosin.

\section{Body Composition}

Total body fat was estimated in 25-week-old mice by dualenergy X-ray absorptiometry using a Hologic QDR 4500 scanner (Hologic, Waltham, MA, USA) as described previously. ${ }^{23}$

\section{Quantitative RT-PCR}

Expression levels of different liver mRNAs were determined by quantitative real-time PCR. Briefly, tissue explants from $12 \mathrm{~h}$ fasted mice were removed, snap frozen in liquid nitrogen and stored at $-80^{\circ} \mathrm{C}$ until use. Samples were homogenized and total RNA was isolated using a NucleoSpin RNA II purification kit (Macherey-Nagel) and then stored at $-80{ }^{\circ} \mathrm{C}$ until use. The RNA integrity was assessed by electrophoresis on agarose gels. cDNA was synthesized from $1 \mu \mathrm{g}$ of total RNA with Moloney murine leukemia virus reverse transcriptase (Promega) using random hexamer nucleotides. Standard curves for these molecules were made to determine the amplification efficiencies of target and reference genes. Quantitative PCR was performed on an ABI Prism 7900 sequence detection system using $100 \mathrm{nM}$ of primers and 
5-20 ng of cDNA. Target mRNA expression was normalized to $\beta$-actin and expressed as a relative value using the comparative threshold cycle $(\mathrm{Ct})$ method $\left(2^{-\Delta \Delta \mathrm{Ct}}\right)$ according to the manufacturer's instructions. Expression levels from genes of interest were normalized to obWT control mice.

\section{Nuclear Protein Extraction}

For nuclear extraction, $200 \mathrm{mg}$ of fresh liver were homogenized with $0.8 \mathrm{ml}$ hypotonic buffer (final concentrations: $10 \mathrm{mM}$ HEPES-KOH, pH 7.9, $10 \mathrm{mM} \mathrm{KCl}, 1.5 \mathrm{mM} \mathrm{MgCl}_{2}$, $0.5 \mathrm{mM}$ DTT, $0.5 \%$ NP-40, $1 \mathrm{mM}$ PMSF and one tablet of the Complete Inhibitor Cocktail (Roche) for each $25 \mathrm{ml}$ of buffer). The homogenates were kept on ice for $20 \mathrm{~min}$. After mixing, the samples were centrifuged at $2000 \mathrm{~g}$, at $4{ }^{\circ} \mathrm{C}$ during $3 \mathrm{~min}$. The cytoplasmic fractions were saved and the pellets resuspended in $180 \mu \mathrm{l}$ hypertonic buffer (final concentrations: $20 \mathrm{mM}$ HEPES-KOH, pH 7.9, $400 \mathrm{mM} \mathrm{NaCl}, 1.5 \mathrm{mM} \mathrm{MgCl}_{2}$, $0.5 \mathrm{mM}$ DTT, $0.2 \mathrm{mM}$ EDTA, $15 \%$ glycerol, $1 \mathrm{mM}$ PMSF and one tablet of the Complete Inhibitor Cocktail (Roche) for each $25 \mathrm{ml}$ of buffer). After $30 \mathrm{~min}$ incubation on ice, the samples were centrifuged at $10000 \mathrm{~g}$, at $4{ }^{\circ} \mathrm{C}$ for $10 \mathrm{~min}$. The supernatant containing the nuclear proteins were kept at $-80^{\circ} \mathrm{C}$ for analyses of protein concentration and western blotting.

\section{Western Blotting}

Following the extraction procedure outlined above, the cytoplasmic and nuclear fractions were analyzed by western blotting. After separation by SDS-PAGE, proteins were transferred onto nitrocellulose membranes, which were blocked with $5 \%$ milk for $1 \mathrm{~h}$ at room temperature. Membranes were incubated overnight with primary antibodies (FKHR - sc-11350, Santa Cruz), washed with tris-buffered saline containing $0.1 \%$ Tween 20 and incubated with peroxidase-conjugated secondary antibodies for $1 \mathrm{~h}$ at room temperature. Membranes were washed, incubated with $\mathrm{Lu}-$ miGlochem iluminescence reagent and exposed on film.

\section{Pyruvate Challenge}

Twenty-four-hour food-deprived mice were i.p. injected with sodium pyruvate $(0.5 \mathrm{~g} / \mathrm{kg})$ for the pyruvate challenge test. Blood samples were taken from the tail vein immediately before and at various time points $(30-240 \mathrm{~min})$ after the pyruvate load.

\section{Intraportal BK Injection}

Lean wild-type C57BL/6J mice at the age of 3 months were anesthetized with fluoretane. The body temperature was kept constant by laying the mice onto a $37-{ }^{\circ} \mathrm{C}$-heating plate. The abdominal cavity was opened and four bolus of $10^{-3} \mathrm{M} \mathrm{BK}$ or saline was injected into the portal vein each 5 min totaling $100 \mu \mathrm{l}$ of solution. After $30 \mathrm{~min}$, fragments of the liver were collected and quickly frozen in liquid nitrogen until use for RNA extraction.

\section{Cell Culture}

Rat hepatoma cells (FAO) were cultured in RPMI 1640 supplemented with $10 \%$ FBS. Insulin, cAMP (N6,2'-O-dibutyryladenosine $3^{\prime}, 5^{\prime}$-cyclic monophosphate sodium salt), BK and HOE140 were purchased from Sigma (St Louis, MO, USA). Groups were divided into $6 \mathrm{~h}$ fasting (without FBS) and a fed state group, and tested with $\mathrm{BK}\left(10^{-6} \mathrm{M}\right)$ or HOE140 $\left(10^{-6} \mathrm{M}\right)+\mathrm{BK}\left(10^{-6} \mathrm{M}\right)$ under three conditions: control, with insulin $(1 \mathrm{unit} / \mathrm{l})$ or with cAMP $(10 \mu \mathrm{M})$. The cells were incubated during $3 \mathrm{~h}$ and the tRNA was extract for quantitative RT-PCR analysis using the Invisorb Spin Universal RNA Mini Kit (Invitek, Berlin, Germany).

\section{Statistical Analysis}

All values are expressed as mean \pm s.e.m. Statistical analyses were carried out using the two-tailed Student's unpaired $t$ test to compare two independent groups or ANOVA followed by Bonferroni's test to compare more than two groups. Significance was rejected at $P \geq 0.05$.

\section{RESULTS \\ BKB2R Deficiency Potentiates Hyperglycemia and Reduces Glucose Tolerance in obWT}

The BKB2R has been shown to promote glucose uptake and GLUT4 translocation in muscle and adipose tissue through a insulin-dependent mechanism. ${ }^{10,11}$ In the absence of BKB2R, mice showed normal insulin sensitivity but reduced glucose tolerance (Figures 1a-f). Additionally, 6-month-old obB2KO mice displayed a higher fasting hyperglycemia when compared with obWT $(162.3 \pm 28.2 \mathrm{mg} / \mathrm{dl} v s 85.25 \pm 13.3 \mathrm{mg} / \mathrm{dl}$, Figure 1g). Interestingly, this difference was observed only in older mice. In fact, it has been shown that glucose metabolism is improved in ob/ob mice at the age of 20 weeks, ${ }^{24-26}$ but this adaptation seems to be blunted in obB2KO mice. In our experiments, we observed that 6-month-old obWT mice showed lower glycemia than 3-month-old obWT mice (Figure 1g). This correlates with a decrease in serum insulin levels in these animals (Figure 1h), indicating that increased insulin secretion is not the reason for the improvement in basal glycemia.

\section{BKB2R Deficiency Does not Affect Obesity or Fat Accumulation in the ob/ob Model.}

Deficiency of leptin in $o b / o b$ mice causes severe obesity. ObB2KO mice had similar body masses $(60.55 \pm 3.94$ vs $66.70 \pm 7.38$; obWT $v s$ obB2KO, respectively), similar growth curves and similar body compositions (fat mass = $68.80 \pm 2.97 \%$ vs $70.61 \pm 3.85 \%$; lean mass $17.93 \pm 2.23 \%$ vs $20.61 \pm 3.66 \%$, obWT vs obB2KO, respectively) than their controls (Figure 2a-d). Body mass of the obB2KO mice was higher during some weeks (18-25 weeks of age) but no significant difference was found after 26 weeks (Figure 2a). It is known that body fat distribution has a role in metabolism and insulin sensitivity. ${ }^{27,28}$ Fat distribution in obB2KO mice was similar to their controls when analyzed by dissection 

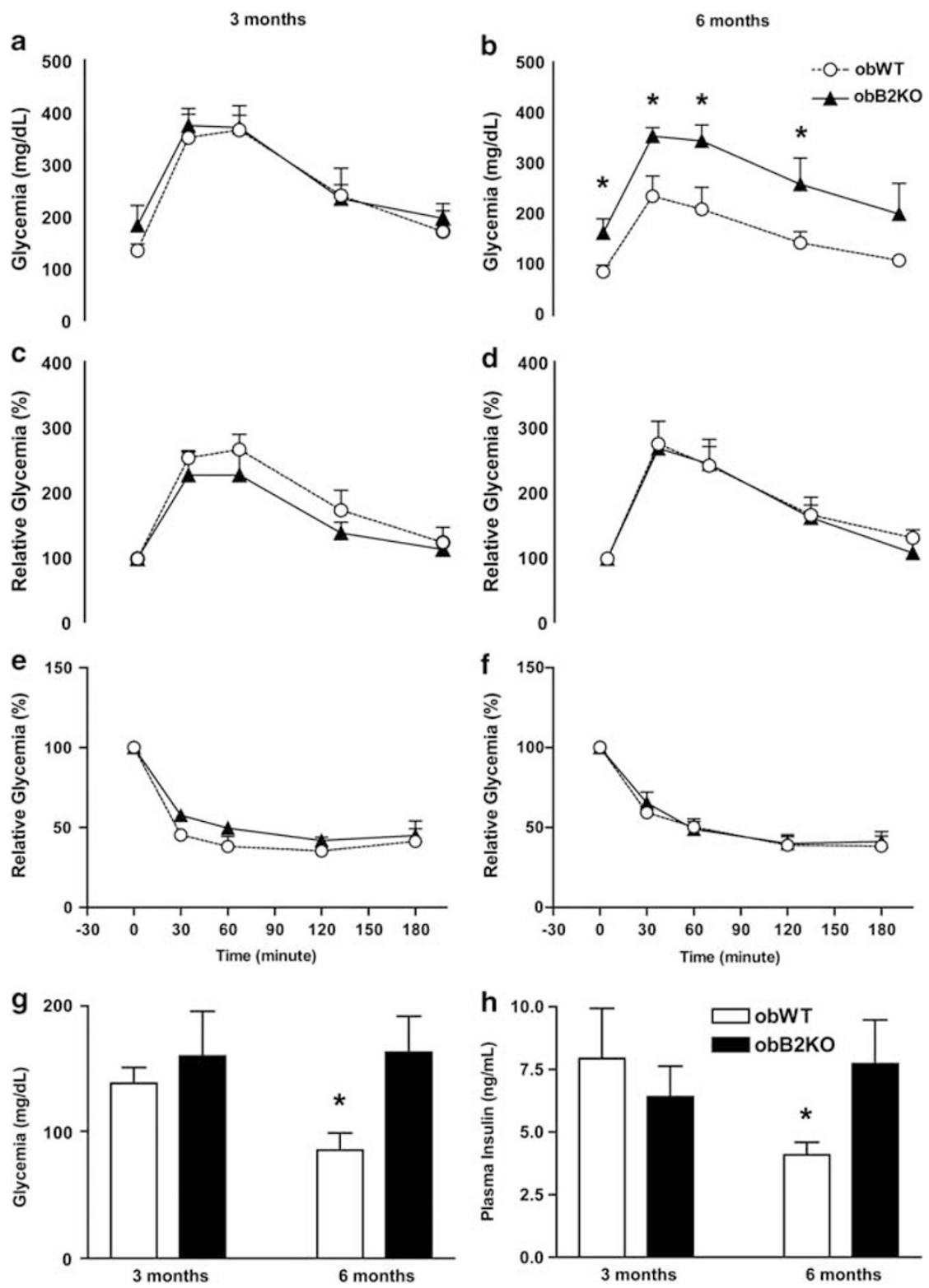

Figure 1 Reduction of basal glycemia and insulinemia in 6-month-old obese mice (obWT) mice. Glucose tolerance test (a-d) and insulin tolerance test $(\mathbf{e}, \mathbf{f})$ in 3- and 6-month-old mice, $n=6$; (g) fasting glycemia comparing 3- and 6-month-old mice, $n=6$; (h) plasma insulin levels, $n=6$. All tests were carried out with the animals after $12 \mathrm{~h}$ of fasting. Values are presented as mean \pm s.e.m., $n>5,{ }^{*} P<0.05$ and ${ }^{* *} P<0.01$.

(Figure 2d). Moreover, the mass of spleen, pancreas, kidney, skeletal muscle (gastrocnemius), heart and liver was not different between the groups (Figures $2 \mathrm{e}$ and $4 \mathrm{c}$ ).

\section{The Gluconeogenesis Pathway is Upregulated in obB2KO mice}

In T2DM patients, increased gluconeogenesis was identified as the main cause of fasting hyperglycemia. ${ }^{29}$ We thus examined the main organ of gluconeogenesis, the liver, and found that the expression of BKB2R mRNA was significantly increased with age in obWT mice $(2.44 \pm 0.48$ fold, $n=6$, Figure 3a), coinciding with the improvement in glucose metabolism. To test the gluconeogenesis pathway we used the pyruvate challenge test to compare the capacity of obWT and obB2KO mice to produce glucose from this substrate. The test was carried out after $24 \mathrm{~h}$ of fasting and showed a more prominent increase of glucose production in obB2KO mice (Figure 3b), mainly 180 and $240 \mathrm{~min}$ after the injection. This increase in glucose production indicates increased gluconeogenesis in obB2KO mice, suggesting that BKB2R deficiency can influence this pathway in obWT.

\section{Expression of Gluconeogenesis Regulatory Enzymes is Increased in obB2KO Mice}

To assess the mechanism through which BKB2R deficiency could modulate glucose production, we analyzed the 

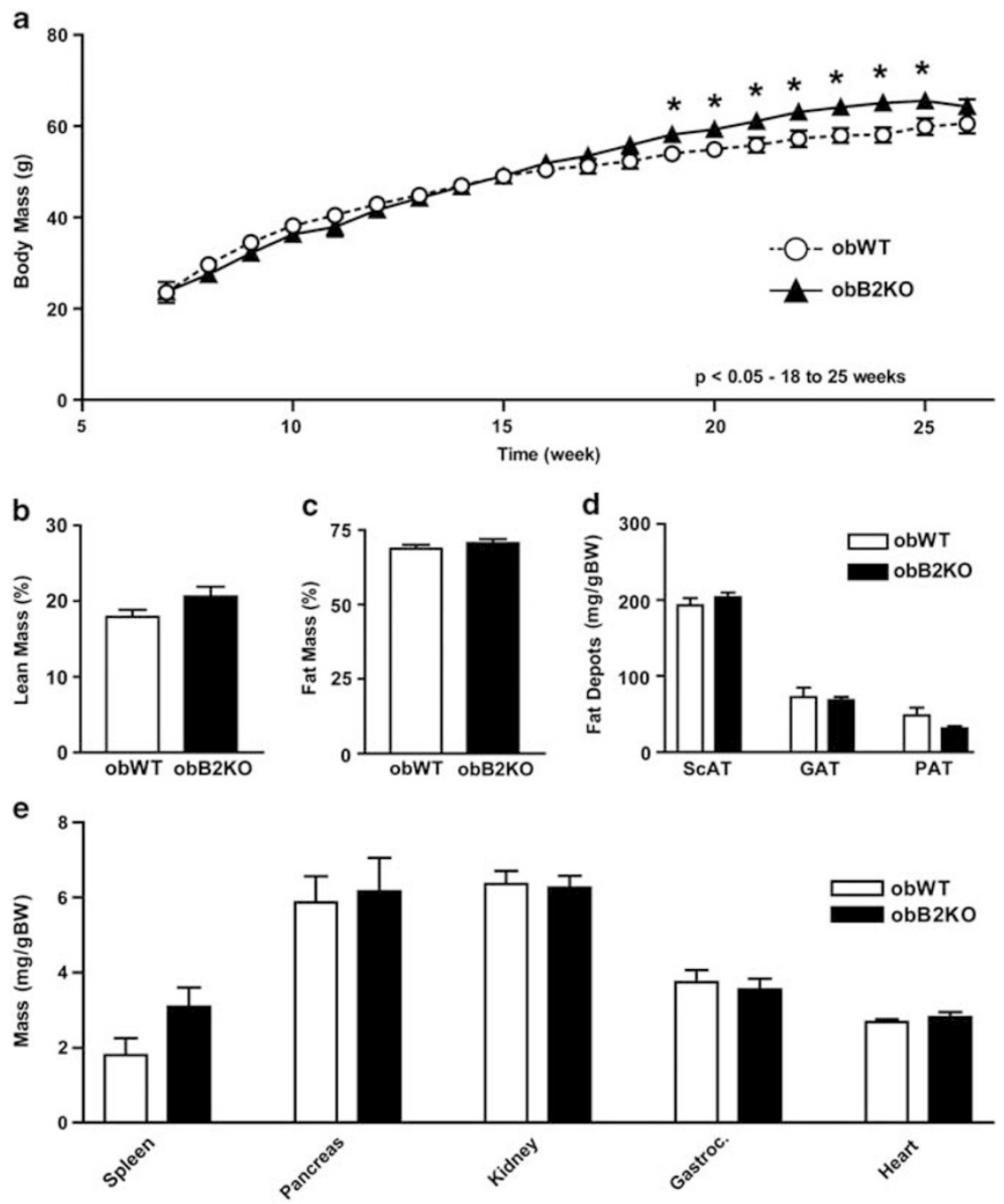

Figure 2 Obesity and fat accumulation in obese mice lacking the bradykinin B2 receptor (obB2KO). (a) Body mass of obB2KO and obese mice (obWT) mice up to 26 weeks of age; (b, c) body composition analyzed by densitometry in 23-week-old mice; (d) mass of fat depots obtained from 30-week-old mice; SCAT, subcutaneous adipose tissue; GAT, gonadal adipose tissue; PAT, perirenal adipose tissue; and (e) mass of organs of 30-week-old mice, gastrocnemius muscle (Gastroc). Values are presented as mean \pm s.e.m., $n=8,{ }^{*} P<0.05$.

expression level of mRNAs coding for enzymes and factors involved in hepatic gluconeogenesis and found increased expression of G6Pase (eight-fold), PEPCK (three-fold), FoxO1 (four-fold) and peroxisome proliferator-activated receptor gamma co-activator 1-alpha (PGC-1a, seven-fold) in liver of obB2KO when compared with obWT (Figure 4a). G6Pase and PEPCK are important regulatory enzymes for activation of the gluconeogenesis pathway and both enzymes are transcriptionally controlled by FoxO1. ${ }^{21}$ The 25hydroxycholesterol 7-alpha-hydroxylase (CYP7b1) expression is dramatically decreased. Additionally, we found a decrease in the expression of glucokinase (GCK) mRNA in obB2KO. This enzyme is known to regulate the catabolism of glucose in hepatocytes by phosphorylation of glucose to glucose-6phosphate. ${ }^{30}$ Other genes related to lipid metabolism in the liver such as hepatocyte nuclear factor 4 alpha, 3-hydroxy3-methyl-glutaryl-CoA reductase, sterol regulatory element- binding transcription factor 1, carnitine palmitoyltransferase1 and glycerol-3-phosphate acyltransferase were not different in obB2KO mice in comparison with obWT mice (Figure 4a). Consistent with the role of these enzymes in lipid metabolism, liver histology showed no improvement of hepatic steatosis in obB2KO when compared with obWT mice (Figure $4 \mathrm{~b}$ ). Liver mass was also similar between obB2KO and obWT ( $41.43 \pm 7.83 \mathrm{mg} / \mathrm{g} v s \quad 40.83 \pm 6.83 \mathrm{mg} / \mathrm{g}$ body weight, respectively; Figure $4 \mathrm{c})$.

\section{Expression and Cellular Distribution of Fox01 Protein is Affected in obB2KO Mice}

The nuclear exclusion of FoxO1 is an important mechanism to regulate glucose metabolism in the liver. Insulin can inhibit gluconeogenesis by Akt-mediated phosphorylation and consequent nuclear exclusion of FoxO1. ${ }^{21}$ As a surrogate for the amount of functional FoxO1 in the hepatic cells of obWT 
and obB2KO mice, we performed western blot analysis of nuclear extracts of random fed and $24 \mathrm{~h}$ fasted mice. These analyses showed higher amounts of nuclear FoxO1 in the liver of fed, but not fasted obB2KO mice when compared with control mice (Figure 5).

\section{BK Injection into the Portal Vein Acutely Decreases the Expression of FoxO1 and PEPCK in Liver}

To determine if BK could influence the expression of the gluconeogenesis regulatory enzymes in vivo, wild-type mice
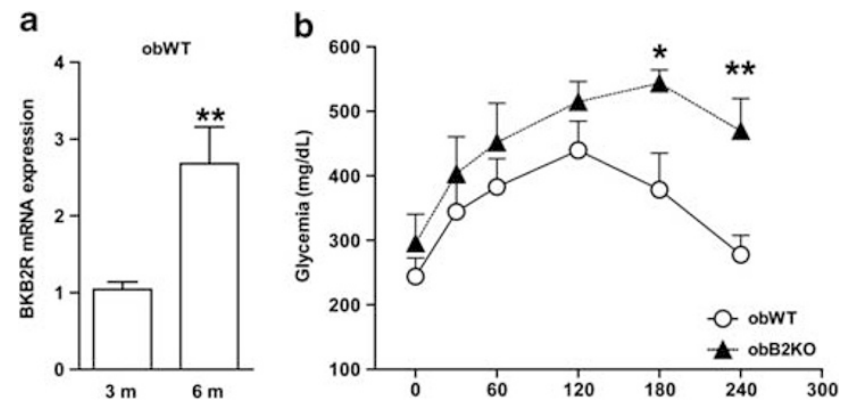

Figure 3 Increased expression of bradykinin B2 receptor (BKB2R) and pyruvate challenge in 6-month-old mice. (a) BKB2R relative mRNA expression of BKB2R mRNA in the liver of 3-and 6-month-old mice after $12 \mathrm{~h}$ fasting, $n=5$. (b) Pyruvate tolerance curve performed in obWT and obese mice lacking the bradykinin B2 receptor (obB2KO) mice (6-month-old, $24 \mathrm{~h}$ starved, $n=5$ ). Values are presented as mean \pm s.e.m., $n>5, * P<0.05$ and ${ }^{*} P<0.01$. were anesthetized with isofluran and a bolus of BK was injected into their portal vein. Mice were killed and liver explants were collected $30 \mathrm{~min}$ after the first bolus. Data showed a significant decrease of the mRNA expression of FoxO1 and PEPCK $(37.3 \pm 14.3 \%$ and $49.1 \pm 19.2 \%$, respectively) when compared with controls (Figure 6). These results therefore confirm that $\mathrm{BK}$ has an active role in the regulation of gluconeogenesis.

\section{BK Effect on the mRNA Expression of Gluconeogenesis Factors in Hepatocytes Culture}

To analyze whether the effect of $\mathrm{BK}$ in liver is due to the direct action of BK on hepatocytes or if it is dependent on other systems related with insulin sensitivity, we cultured rat hepatoma cells (FAO) in different conditions, adding BK alone or with the BKB2R antagonist HOE140. After $3 \mathrm{~h}$, the tRNA was extracted and quantitative RT-PCR analyses were carried out. The cells reacted as expected to insulin or cAMP, respectively, inhibiting or activating the expression of both G6Pase and, PEPCK, when compared with the control cells. FBS starved cells presented increased expression of these factors keeping the same expression profiles in respect to insulin or cAMP addition. BK $\left(10^{-6} \mathrm{M}\right)$ could slightly decrease the mRNA expression of PEPCK and FoxO1, but not G6Pase in isolated FAO cells, and these effects were observed only after FBS starvation and stimulation with cAMP (Figure 7).
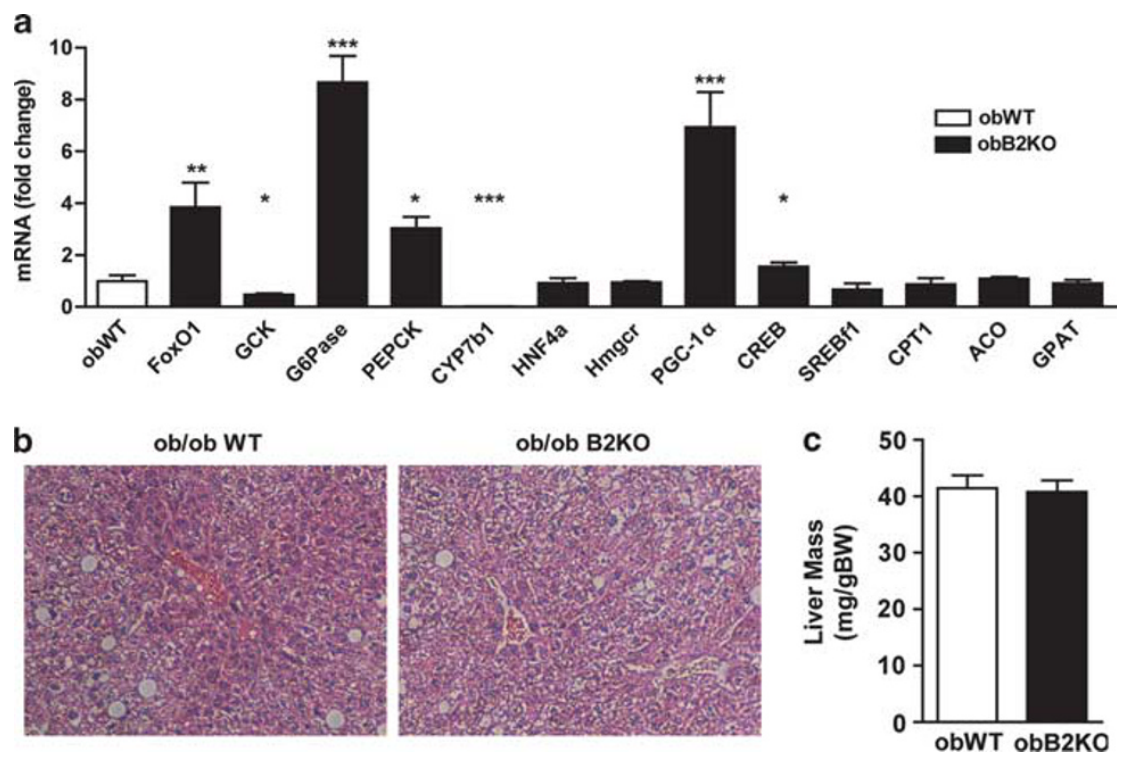

Figure 4 The expression of forkhead box protein $\mathrm{O} 1$ (FoxO1), phosphoenolpyruvate carboxykinase (PEPCK) and glucose-6-phosphatase (G6Pase) is increased in the liver of obese mice lacking the bradykinin B2 receptor (obB2KO) mice. (a) Relative mRNA expression of enzymes involved in glucose and lipid metabolism in the liver: FoxO1, glucokinase (GCK), G6Pase, PEPCK, 25-hydroxycholesterol 7-alpha-hydroxylase (CYP7b1), hepatocyte nuclear factor 4 alpha (HNF4a), 3-hydroxy-3-methylglutaryl-CoA reductase (Hmgcr), peroxisome proliferator-activated receptor gamma co-activator 1-alpha (PGC-1a); cyclic AMP-responsive element-binding protein 1 (CREB), sterol regulatory element-binding protein 1 (SREBPf1); carnitine palmitoyltransferase1 (CPT1); acyl-CoA oxidase (ACO); glycerol-3-phosphate acyltransferase (GPAT); (b) representative microphotography of liver sections, stained with hematoxylin and eosin, of the obese mice (obWT) and obB2KO mice, showing a similar pattern of steatosis; (c) liver mass of 30-week-old mice; ${ }^{*} P<0.05,{ }^{* *} P<0.01,{ }^{* * *} P<0.001, n=5$. 

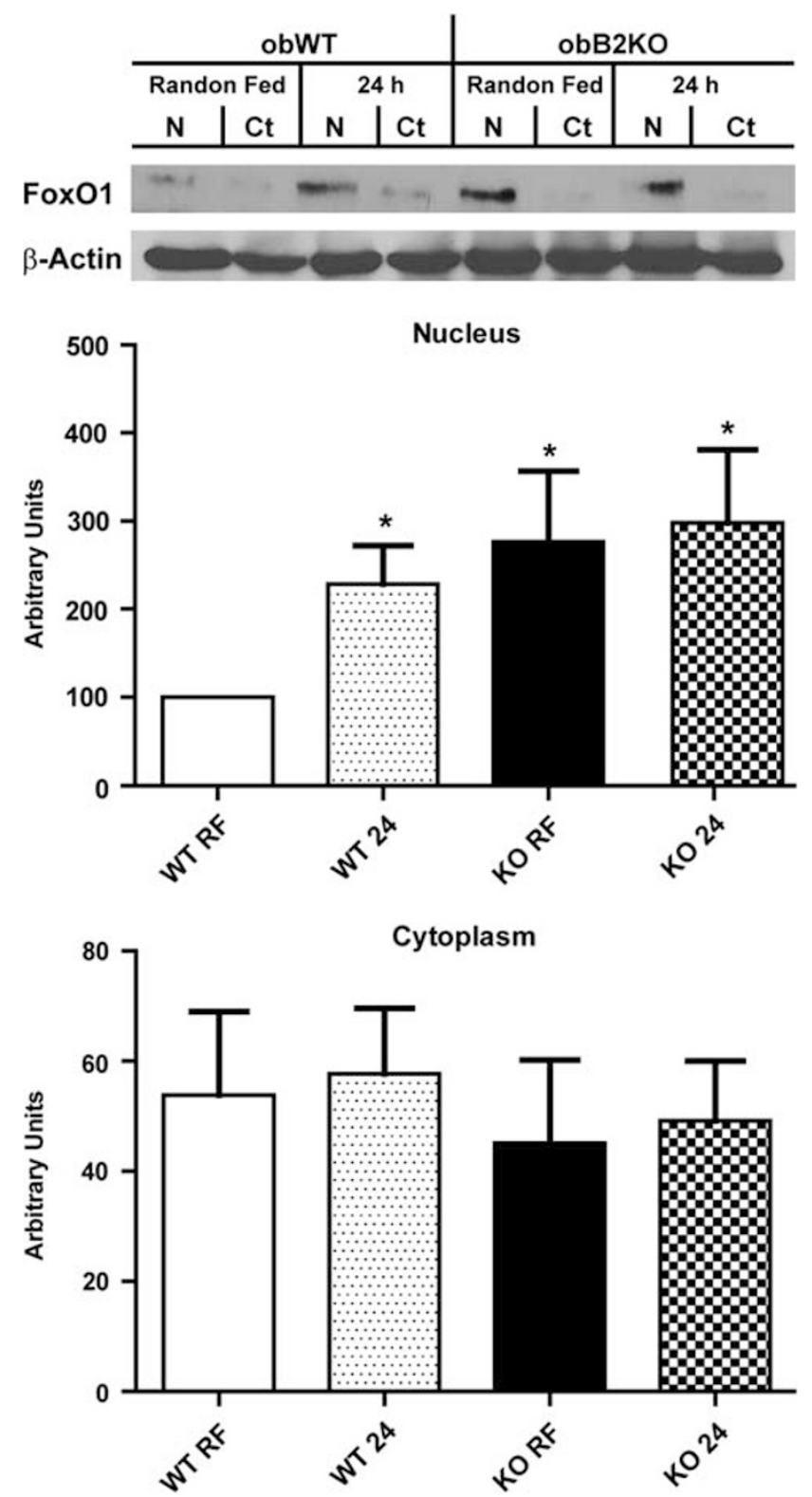

Figure 5 Changes in the regulation of the nuclear exclusion of the forkhead box protein $\mathrm{O} 1$ (FoxO1). Analysis and representative image of western blots of nuclear and cytoplasmic fractions of the liver of obBKB2R mice and controls, either random fed or $24 \mathrm{~h}$ starved, $n=4$, $\mathrm{RF}=$ random fed, $24=24 \mathrm{~h}$ starved. Values are presented as mean + s.e.m., ${ }^{*} P<0.05$.

\section{DISCUSSION}

In order to study the participation of BK in the pathophysiology of obesity and T2DM, we generated a genetically modified mouse deficient in leptin and the BKB2R. These animals are as obese as their controls, which are deficient only in leptin. On the other hand, obB2KO mice show higher hyperglycemia and increased production of glucose during a pyruvate challenge. Interestingly, these differences appear only when the animals are 6 months old.

As the most important organ for gluconeogenesis is the liver, ${ }^{31}$ we assessed the expression of $\mathrm{BKB} 2 \mathrm{R}$ in the liver of

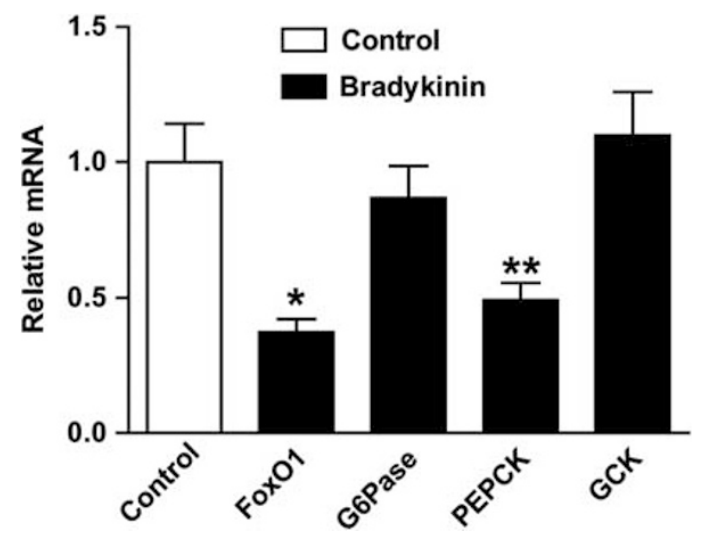

Figure 6 Effects of portal injection of bradykinin (BK) in anesthetized WT lean mice. Relative mRNA expression of enzymes involved in glucose metabolism in the liver after 30 min of intraportal BK bolus injection; $n=4$ : forkhead box protein 01 (FoxO1), glucose-6-phosphatase (G6Pase), phosphoenolpyruvate carboxykinase (PEPCK) and glucokinase (GCK). Values are presented as mean \pm s.e.m. of relative changes of mRNA levels when compared with the controls, ${ }^{*} P<0.05,{ }^{* *} P<0.01$ relative to control.

obWT animals of two different ages. As previously described by several studies, the glycemia in obWT mice reduces when animals are 6-month-old compared with younger animals. ${ }^{24-26}$ Our results confirm this observation and demonstrate that it coincides with an increase in BKB2R mRNA expression in the liver of obWT mice with age, suggesting that hepatic BKB2R might be involved in this process.

Although obB2KO mice do not show morphological changes in liver, the mRNA expression of the most important factors for activation of the gluconeogenesis was increased in the liver of these animals compared with controls. FoxO1, an important transcriptional factor to regulate gluconeogenesis in liver ${ }^{21}$ was increased at the mRNA level in the liver of obB2KO mice. This result is consistent with the increase of G6Pase and PEPCK mRNA expression observed in 6-monthold obB2KO mice. The transcription factors and coactivators involved in the control of gluconeogenesis have been studied by several authors and confirmed by chromatin immunoprecipitation assay. ${ }^{32-36}$ FoxO1 is also known to inhibit the mRNA expression of CYP7A1. ${ }^{37}$ Consistently, CYP7b1 expression is dramatically decreased in the liver of obB2KO mice. These results together with increased glucose production and higher hyperglycemia in obB2KO mice point to a chronic upregulation of the gluconeogenesis pathway in obB2KO mice.

One way of regulating the activity of FoxO1 is by the phosphorylation and subsequent nuclear exclusion of this factor in the cell. ${ }^{38}$ The protein kinase B (AKT) is the main kinase responsible for nuclear exclusion of FoxO1. ${ }^{39}$ Under conditions of abundant glucose, ie, during fed state, insulin is released and promotes activation of AKT in the liver with subsequent FoxO1 phosphorylation and nuclear exclusion. ${ }^{40,41}$ It then results in inhibition of expression of enzymes responsible for gluconeogenesis. ${ }^{42}$ Under random fed regimen, obB2KO mice exhibit an atypical increase in 
a

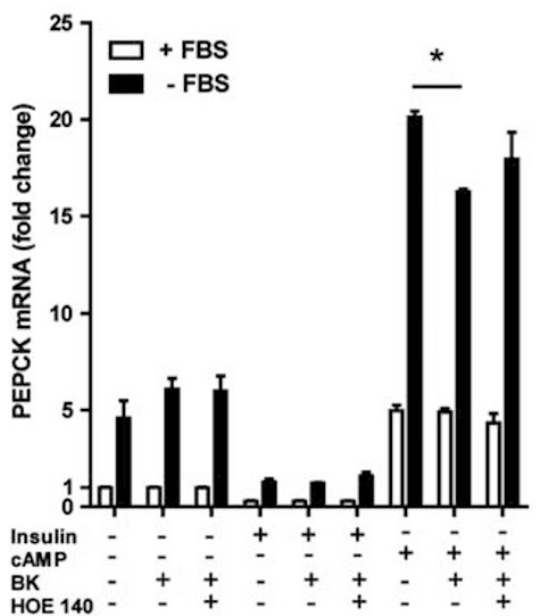

b

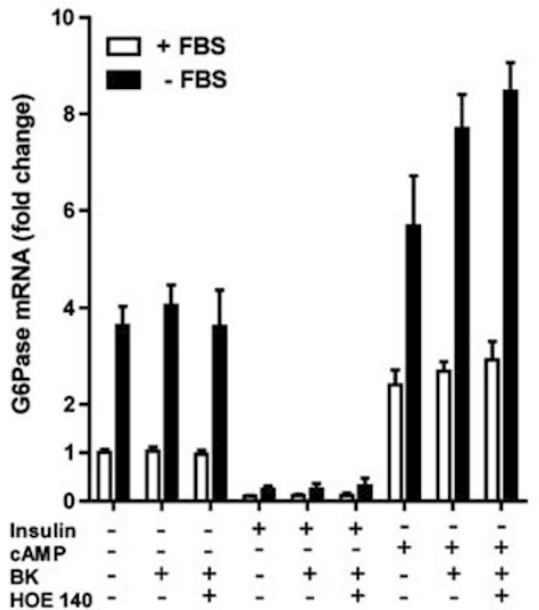

C

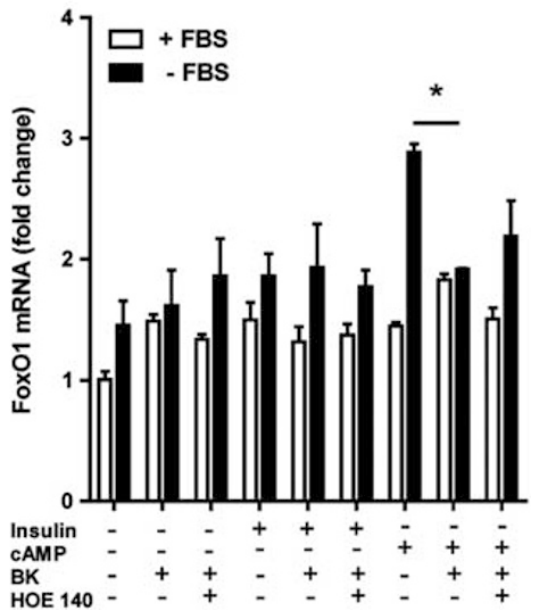

Figure 7 Effect of bradykinin (BK) in cultured hepatome cells (FAO). The cells were distributed in two groups: with or without fetal bovine serum (+FBS or - FBS). Three different conditions were used concerning absence or addition of insulin and cAMP. Each condition was tested with or without BK $\left(10^{-6} \mathrm{M}\right)$ and HOE140 $\left(10^{-6} \mathrm{M}\right)$, a BKB2R antagonist. Values are presented as mean \pm s.e.m., ${ }^{*} P<0.05, n=3$.

nuclear FoxO1 levels. Interestingly, these levels are similar to the levels observed in fasted mice, which suggest that: (1) obB2KO are not responsive to insulin or other signals that inhibit gluconeogenesis in response to feeding; and (2) independently on the feeding status, nuclear FoxO1 is at its maximum levels in obB2KO mice. Thus, the increase in fasting gluconeogenesis should be related to the higher expression of PGC-1a in obB2KO, as it was reported that this co-activator is responsible for activation/stabilization of the transcriptional complex necessary for the transcriptional activity of FoxO1.43 Furthermore, PGC-1a has also been associated with metabolic changes in the liver, especially with the activation of gluconeogenesis. ${ }^{43}$

All these results are in consonance with Hartl et al, ${ }^{44}$ who proposed that the favorable effects of systemic administration of kinins in humans could be mediated by prostaglandins. On the other hand, diet induced liver-insulin-resistance in rats was followed by decreased plasma BK level in a metabolomic analysis ${ }^{45}$ suggesting that the insulin pathway could be involved in metabolic effect of BK in vivo. Although it is unclear whether the mechanism is insulin dependent or not, the present work shows that the KKS is involved in this process.

We also tested the effect of BK in cultured hepatoma cells. In this isolated system, BK had only a slight effect to inhibit PEPCK and FoxO1 expression, but none regarding G6Pase. This effect was blocked by previous incubation with the BKB2R antagonist HOE140. These results are similar to those observed after $\mathrm{BK}$ injection in the portal vein in vivo (Figure 6), suggesting that the chronic effects of $\mathrm{BK}$ in obB2KO mice are also dependent on other systems as suggest by Li et $a l,{ }^{45}$ who showed a cross talking between the KKS and the insulin pathway, ${ }^{45}$ and other several studies that show the influence of $\mathrm{BK}$ in insulin secretion of the pancreatic cells. ${ }^{4-49}$ It is important to highlight that this finding was only observed in cells that were FBS starved during $6 \mathrm{~h}$ and were also stimulated with cAMP, the second messenger of the glucagon receptor pathway.

The model of obesity used in the present work was important to demonstrate the effect of BK in hepatic gluconeogenesis. Duka et al ${ }^{5}$ showed that the lean B2KO mice have significantly higher steady-state insulin levels, significantly lower glucose uptake rates and insulin sensitivity indexes, but did not analyze hepatic gluconeogenesis. We challenged these lean mice with the pyruvate tolerance test (Supplementary Figure S1) and we also carried out hepatic mRNA expression analysis of some gluconeogenesis factors (FoxO1, G6Pase, PEPCK and PGC-1; Supplementary Figure S2). The analyses did not show differences in gluconeogenesis activity or in expression of these factors in the lean $\mathrm{B} 2 \mathrm{KO}$ mice when compared with the lean WT controls, as presented in the supplementary data.

In summary, these results show that the BKB2R participates in the regulation of hepatic glucose production of obWT, but not in lean mice. This scenario takes place with an increase in the expression and a decrease in the nuclear exclusion of FoxO1 and consequent increase in the expression of PEPCK and G6Pase mRNAs. Increased activity of FoxO1 in obB2KO during fasting is also promoted by increased PGC-1a. It points to a protective effect of BK and its analogs in obese, T2DM individuals.

Supplementary Information accompanies the paper on the Laboratory Investigation website (http://www.laboratoryinvestigation.org)

\section{ACKNOWLEDGEMENTS}

This study was supported by grants from FAPESP (06/59081-6), CNPq and CAPES (PROCAD- 0216/05-4).

\section{DISCLOSURE/CONFLICT OF INTEREST}

The authors declare no conflict of interest. 
1. Kahn SE, Hull RL, Utzschneider KM. Mechanisms linking obesity to insulin resistance and type 2 diabetes. Nature 2006;444:840-846.

2. Gill RS, Sharma AM, Gill SS, et al. The impact of obesity on diabetes mellitus and the role of bariatric surgery. Maturitas, 69:137-140.

3. Travers ME, McCarthy MI. Type 2 diabetes and obesity: genomics and the clinic. Hum Genet 2011;130:41-58.

4. Dias JP, Couture R. Blockade of kinin $B(1)$ receptor reverses plasma fatty acids composition changes and body and tissue fat gain in a rat model of insulin resistance. Diabetes Obes Metab 2012;14:244-253.

5. Duka I, Shenouda S, Johns $C$, et al. Role of the $B(2)$ receptor of bradykinin in insulin sensitivity. Hypertension 2001;38:1355-1360.

6. Batista EC, Batista EC, Ramalho JD, et al. Swimming training exacerbates pathological cardiac hypertrophy in kinin B2 receptordeficient mice. Int Immunopharmacol 2008;8:271-275.

7. Mori MA, Araujo RC, Reis FC, et al. Kinin B1 receptor deficiency leads to leptin hypersensitivity and resistance to obesity. Diabetes 2008, 57:1491-1500

8. Kishi $\mathrm{K}$, Muromoto $\mathrm{N}$, Nakaya $\mathrm{Y}$, et al. Bradykinin directly triggers GLUT4 translocation via an insulin-independent pathway. Diabetes 1998;47:550-558.

9. Araujo RC, Mori MA, Merino VF, et al. Role of the kinin B1 receptor in insulin homeostasis and pancreatic islet function. Biol Chem 2006;387:431-436.

10. Isami S, Kishikawa H, Araki $E$, et al. Bradykinin enhances GLUT4 translocation through the increase of insulin receptor tyrosine kinase in primary adipocytes: evidence that bradykinin stimulates the insulin signalling pathway. Diabetologia 1996:39:412-420.

11. Miyata T, Taguchi T, Uehara M, et al. Bradykinin potentiates insulinstimulated glucose uptake and enhances insulin signal through the bradykinin B2 receptor in dog skeletal muscle and rat L6 myoblasts. Eur J Endocrinol 1998;138:344-352.

12. Beard KM, Lu H, Ho K, et al. Bradykinin augments insulin-stimulated glucose transport in rat adipocytes via endothelial nitric oxide synthase-mediated inhibition of Jun NH2-terminal kinase. Diabetes 2006;55:2678-2687.

13. Shiuchi $T$, Nakagami $H$, Iwai $M$, et al. Involvement of bradykinin and nitric oxide in leptin-mediated glucose uptake in skeletal muscle. Endocrinology 2001;142:608-612.

14. Roh S, Choi S, Lim I. Involvement of protein kinase A in nitric oxide stimulating effect on a $\mathrm{BK}(\mathrm{Ca})$ channel of human dermal fibroblasts. J Invest Dermatol 2007;127:2533-2538.

15. Shiuchi T, Cui TX, Wu L, et al. ACE inhibitor improves insulin resistance in diabetic mouse via bradykinin and NO. Hypertension 2002;40: 329-334.

16. Adam A, Leclair $\mathrm{P}$, Montpas $\mathrm{N}$, et al. Altered cardiac bradykinin metabolism in experimental diabetes caused by the variations of angiotensin-converting enzyme and other peptidases. Neuropeptides, 44:69-75.

17. Vora JP, Oyama TT, Thompson MM, et al. Interactions of the kallikreinkinin and renin-angiotensin systems in experimental diabetes. Diabetes 1997:46:107-112.

18. Tschope C, Schultheiss HP, Walther T. Multiple interactions between the renin-angiotensin and the kallikrein-kinin systems: role of ACE inhibition and AT1 receptor blockade. J Cardiovasc Pharmacol 2002:39:478-487.

19. Carvalho CR, Thirone AC, Gontijo JA, et al. Effect of captopril, losartan, and bradykinin on early steps of insulin action. Diabetes 1997;46: 1950-1957.

20. Geisler SA, Felisberto-Junior AM, Tavoni TM, et al. Participation of the liver gluconeogenesis in the glibenclamide-induced hypoglycaemia in rats. Cell Biochem Funct, 29:81-86.

21. Cheng Z, White MF. Targeting Forkhead box 01 from the concept to metabolic diseases: lessons from mouse models. Antioxid Redox Signal, 14:649-661.

22. Barros CC, Almeida SS, Mori MA, et al. Efficient method for obtaining Lep(ob)/Lep(ob)-derived animal models using adipose tissue transplantations. Int J Obes 2009;33:938-944.

23. Castro $\mathrm{CH}$, Shin CS, Stains JP, et al. Targeted expression of a dominantnegative $\mathrm{N}$-cadherin in vivo delays peak bone mass and increases adipogenesis. J Cell Sci 2004;117(Pt 13):2853-2864.

24. Carlsson PO, Andersson A, Jansson L. Influence of age, hyperglycemia, leptin, and NPY on islet blood flow in obese-hyperglycemic mice. Am J Physiol 1998;275(4 Pt 1):E594-E601.
25. Westman S. Development of the obese-hyperglycaemic syndrome in mice. Diabetologia 1968;4:141-149.

26. Lindstrom P. The physiology of obese-hyperglycemic mice [ob/ob mice]. ScientificWorldJournal 2007;7:666-685.

27. Demerath EW, Reed $\mathrm{D}$, Rogers $\mathrm{N}$, et al. Visceral adiposity and its anatomical distribution as predictors of the metabolic syndrome and cardiometabolic risk factor levels. Am J Clin Nutr 2008;88:1263-1271.

28. Gallagher D, Kelley DE, Yim JE, et al. Adipose tissue distribution is different in type 2 diabetes. Am J Clin Nutr 2009;89:807-814.

29. Roden $M$, Bernroider E. Hepatic glucose metabolism in humans-its role in health and disease. Best Pract Res Clin Endocrinol Metab 2003; 17:365-383.

30. Beer NL, van de Bunt $M$, Colclough $K$, et al. Discovery of a novel site regulating glucokinase activity following characterization of a new mutation causing hyperinsulinemic hypoglycemia in humans. J Biol Chem, 286:19118-19126.

31. Samuel VT, Beddow SA, Iwasaki T, et al. Fasting hyperglycemia is not associated with increased expression of PEPCK or G6PC in patients with Type 2 Diabetes. Proc Natl Acad Sci USA 2009;106:12121-12126.

32. Cassuto $\mathrm{H}$, Kochan $\mathrm{K}$, Chakravarty $\mathrm{K}$, et al. Glucocorticoids regulate transcription of the gene for phosphoenolpyruvate carboxykinase in the liver via an extended glucocorticoid regulatory unit. J Biol Chem 2005;280:33873-33884.

33. Mutel E, Gautier-Stein A, Abdul-Wahed A, et al. Control of blood glucose in the absence of hepatic glucose production during prolonged fasting in mice: induction of renal and intestinal gluconeogenesis by glucagon. Diabetes, 60:3121-3131.

34. Wei $D$, Tao $R$, Zhang $Y$, et al. Feedback regulation of hepatic gluconeogenesis through modulation of SHP/NrOb2 gene expression by Sirt1 and FoxO1. Am J Physiol Endocrinol Metab, 300:E312-E320.

35. Yoon YS, Lee MW, Ryu D, et al. Suppressor of MEK null (SMEK)/protein phosphatase 4 catalytic subunit (PP4C) is a key regulator of hepatic gluconeogenesis. Proc Natl Acad Sci USA, 107:17704-17709.

36. Zhu LL, Liu Y, Cui AF, et al. PGC-1alpha coactivates estrogen-related receptor-alpha to induce the expression of glucokinase. Am J Physiol Endocrinol Metab, 298:E1210-E1218.

37. Li T, Ma H, Park YJ, et al. Forkhead box transcription factor $\mathrm{O} 1$ inhibits cholesterol 7alpha-hydroxylase in human hepatocytes and in high fat diet-fed mice. Biochem Biophys Acta 2009;1791:991-996.

38. Obsil T, Obsilova V. Structure/function relationships underlying regulation of FOXO transcription factors. Oncogene 2008;27: 2263-2275.

39. Vogt PK, Jiang $H$, Aoki M. Triple layer control: phosphorylation, acetylation and ubiquitination of FOXO proteins. Cell Cycle 2005;4: 908-913

40. Cintra DE, Pauli JR, Araujo EP, et al. Interleukin-10 is a protective factor against diet-induced insulin resistance in liver. J Hepatol 2008;48: 628-637.

41. Dong XC, Copps KD, Guo S, et al. Inactivation of hepatic Foxo1 by insulin signaling is required for adaptive nutrient homeostasis and endocrine growth regulation. Cell Metab 2008;8:65-76.

42. Barthel A, Schmoll D. Novel concepts in insulin regulation of hepatic gluconeogenesis. Am J Physiol Endocrinol Metab 2003;285:E685-E692.

43. Soyal S, Krempler F, Oberkofler $H$, et al. PGC-1alpha: a potent transcriptional cofactor involved in the pathogenesis of type 2 diabetes. Diabetologia 2006;49:1477-1488.

44. Hartl WH, Jauch KW, Wolfe RR, et al. Effects of kinins on glucose metabolism in vivo. Horm Metab Res Suppl 1990;22:79-84.

45. Li LO, Hu YF, Wang L, et al. Early hepatic insulin resistance in mice: a metabolomics analysis. Mol Endocrinol, 24:657-666.

46. Saito $Y$, Kato $M$, Kubohara $Y$, et al. Bradykinin increases intracellular free $\mathrm{Ca} 2+$ concentration and promotes insulin secretion in the clonal beta-cell line, HIT-T15. Biochem Biophys Res Commun 1996;221: 577-580.

47. Moura AS. Bradykinin enhances membrane electrical activity of pancreatic beta cells in the presence of low glucose concentrations. Braz J Med Biol Res 2000;33:1089-1092.

48. Yang C, Chao J, Hsu WH. The effect of bradykinin on secretion of insulin, glucagon, and somatostatin from the perfused rat pancreas. Metabolism 1997:46:1113-1115.

49. Yang C, Lee B, Chen TH, et al. Mechanisms of bradykinin-induced insulin secretion in clonal beta cell line RINm5F. J Pharmacol Exp Ther 1997;282:1247-1252. 